\title{
Safety aspects of hysteroscopy, specifically in relation to entry and specimen retrieval: a UK survey of practice
}

\author{
S. H. Walker ${ }^{*}$ and L. Gokhale
}

\begin{abstract}
Background: The purpose of this study is to evaluate current practice amongst gynaecologists across the UK, regarding safety aspects of inpatient hysteroscopy under anaesthesia, specifically in relation to entry and specimen retrieval.

A survey was created using survey monkey. The first round was circulated to all registrar trainees and consultant gynaecologists across Wales. Following a good response, the survey was then circulated to all members of the British Society of Gynaecological Endoscopy (BSGE).
\end{abstract}

Results: There were 212 responses including, 140 consultants, 36 senior registrars, 17 junior registrars and 18 clinical nurse specialists. In total, 136 out of 212 (64.7\%) always perform a vaginal examination prior to hysteroscopy. 10.4\% always sound the uterus, and 5.2\% always dilate the uterus prior to insertion of the hysteroscope. Twenty-three consultants, six senior registrars, three junior registrars and one clinical nurse specialist knew how to position the internal cervical os as visualised through the scope when using a $30^{\circ}$ hysteroscope. $35.8 \%$ of candidates always perform a post-procedure cavity check, and $9 \%$ use suction to flush the cavity to aid vision during the postprocedure cavity check. The majority (76\%) predicted dilatation as the stage most likely to cause uterine perforation and predicted the most likely site for perforation as the posterior uterine wall in the anteverted uterus and the anterior uterine wall in the retroverted uterus.

Conclusion: This study highlights varied practice across the UK regarding safety aspects of hysteroscopy, in relation to entry and specimen retrieval. There is a need for increased awareness of the risks of hysteroscopy and paramount precautions that should be performed routinely as part of their practice. Standardised guidelines may be a beneficial tool to help bring about this change in practice, leading to a reduction in uterine perforation rates.

Keywords: Hysteroscopy, Uterine perforation, Specimen retrieval

\section{Background}

The hysteroscope has become a standard part of a gynaecologists' armamentarium, with operative hysteroscopy increasing as a surgical alternative for various gynaecological problems [1]. Uterine perforation is an uncommon but potentially serious complication of hysteroscopy. Guidance from the Royal College of Obstetricians and Gynaecologists (RCOG) on best practice in outpatient hysteroscopy estimates a perforation rate of $0.007-1.7 \%$ [2]. With higher rates of

\footnotetext{
* Correspondence: sarah.walker30@nhs.net

Department of Obstetrics and Gynaecology, Royal Gwent Hospital, Aneurin Bevan University Health Board, Newport, UK
}

$1.6 \%$ reported for operative hysteroscopy [3, 4]. Risk factors include cervical stenosis, tortuous cervical canal and deviated uterine cavity as a result of fibroids $[2,5]$.

Outpatient hysteroscopy with or without the use of local anaesthesia is now an established technique [1]. It is associated with a lower incidence of uterine trauma due to being performed with smaller-diameter hysteroscopes and under direct vision [2]. The main reasons for failure to successfully perform outpatient hysteroscopy includes cervical stenosis, severe pain, vasovagal reaction and high body mass index (BMI) making access difficult $[2,6]$. Consequently, there will always be a necessity for inpatient hysteroscopy under 
general anaesthetic, and this cohort of women are at higher risk of complications due to increasing operative complexity, higher incidence of cervical stenosis, postmenopausal cervical atrophy and co-morbidities [7].

It has been estimated that $55 \%$ of uterine perforations are entry related (i.e. secondary to sounding, dilatation and insertion of hysteroscope) and $45 \%$ are related to technique used and improper use of the probe $[1,8]$.

Hysteroscopy carries small risks that cannot be eliminated completely, but preventing hysteroscopy complications starts by raising awareness of risks and precautions [1]. Currently there are no clear guidelines regarding safety aspects of inpatient diagnostic and operative hysteroscopy under general anaesthetic.

The aim of this study is to evaluate current practice amongst gynaecologists across the UK regarding safety aspects of inpatient hysteroscopy under general anaesthetic, specifically in relation to entry and specimen retrieval. Results from the survey may help determine if practice needs to change and whether there is a need for standardised guidelines on inpatient hysteroscopy under general anaesthetic.

\section{Method}

A survey was created using survey monkey. The first round was circulated to all gynaecological specialitytraining registrar doctors in their third to seventh year of training (ST3-7 trainees) and consultant gynaecologists across Wales in December 2016. Following a good response to this, the survey was then circulated to all members of the British Society of Gynaecological Endoscopy (BSGE) in June 2017. No ethical approval was required as the survey was optional and anonymous and study aims explained to all candidates prior to performing the survey.

Questions were based on safety aspects of all the stages of hysteroscopy, which can lead to uterine perforation. The survey specified for inpatient hysteroscopy under general anaesthetic. Question 1 was whether they routinely perform a vaginal examination prior to hysteroscopy. The next four questions were entry-related; whether they routinely sound and dilate the uterus prior to entry of the hysteroscope, the type of hysteroscope used and technique used when inserting the hysteroscope. Question 6 related to specimen retrieval. Questions 7 and 8 were whether they perform a post-procedure cavity check and whether they use suction to flush the cavity to aid this step.

An additional three questions were included in the survey when it was circulated to members of the BSGE. These included; the anatomical location the candidate thought you are most likely to perforate during hysteroscopy, during which stage of hysteroscopy they are most likely to perforate, and finally whether they use a standard proforma for documentation of their findings in their department.

Results were collated on an excel spreadsheet and analysed. For analysis the grades were split up into consultants, senior registrars (ST5-7), junior registrars (ST3-4) and clinical nurse specialists.

\section{Results}

In total, 212 responses were included in analysis, 83 out of 170 responses (48.8\%) from the first round to gynaecologists across Wales (13 junior registrars, 15 senior registrars, 55 consultants) and 129 out of 983 responses (13.1\%) from the second round to members of the BSGE covering all regions of the UK (18 clinical nurse specialists, 5 junior registrars, 21 senior registrars, 85 consultants).

\section{Hysteroscopic approach and entry-related safety precautions}

As shown in Table 1, in total, 64.2\% (136/212) always carry out a vaginal examination prior to hysteroscopy, with a higher proportion of junior registrars (88.9\%) compared to consultants (59.3\%) always carrying out vaginal examination prior to hysteroscopy. In total, $10.4 \%$ $(22 / 212)$ always sound the uterus before inserting the hysteroscope (15 consultants, 2 senior registrars, 4 junior registrars and 1 clinical nurse specialist). In total, $5.2 \%(11 / 212)$ always dilate, $22.6 \%$ (48/212) never dilate and $72.2 \%(153 / 212)$ sometimes dilate before inserting the hysteroscope (Table 1).

When asking which type of hysteroscope candidate's use, the majority of registrars never use a $0^{\circ}$ hysteroscope, with $13.6 \%$ of consultants and $33.3 \%$ of clinical nurse specialists only using a $0^{\circ}$ hysteroscope. Table 2 summarises the responses given when candidates were asked how they position the internal cervical os as visualised through the scope when using a $30^{\circ}$ scope. Only $16.7 \%(34 / 204)$ knew the correct position being, 'the 6 o'clock position for anteverted uterus and 12 o'clock position for retroverted uterus.' The commonest answer given by $34.8 \%$ (71/204) was 'always the 6 o'clock position', which is the correct answer for an anteverted uterus, followed by 'the way the hysteroscope naturally goes', for which $32.4 \%$ gave as their answer $(66 / 204)$.

\section{Hysteroscopic technique}

Table 3 demonstrates the instruments used by candidates for specimen retrieval. The majority of candidates use a range of instruments depending on availability. Overall, more candidates used polyp forceps (71\%) and curette (58\%), both being blind procedures compared to specimen retrieval under direct vision including myosure (24\%) and resectoscope (10\%). 
Table 1 Summary of response to questions related to safety aspects of hysteroscopy

\begin{tabular}{|c|c|c|c|c|c|c|}
\hline \multirow[t]{2}{*}{ Questions } & \multirow[t]{2}{*}{ Response } & \multicolumn{5}{|c|}{ Number (percentage) } \\
\hline & & Consultants & Senior registrar & Junior registrar & $\begin{array}{l}\text { Clinical nurse } \\
\text { specialist }\end{array}$ & Total \\
\hline \multirow{3}{*}{$\begin{array}{l}\text { Do you carry out a vaginal examination } \\
\text { before hysteroscopy? }\end{array}$} & Always & $83(59.3)$ & $31(86.1)$ & $16(88.9)$ & $6(33.3)$ & $136(64.2)$ \\
\hline & Never & $7(5)$ & $1(2.8)$ & 0 & $2(11.1)$ & $10(4.7)$ \\
\hline & Sometimes & $50(35.7)$ & $4(11.1)$ & $2(11.1)$ & $10(55.6)$ & $66(31.1)$ \\
\hline \multirow{3}{*}{$\begin{array}{l}\text { Do you Sound the uterus before inserting } \\
\text { the hysteroscope? }\end{array}$} & Always & $15(10.7)$ & $2(5.6)$ & $4(22.2)$ & $1(5.6)$ & $22(10.4)$ \\
\hline & Never & $77(55)$ & $20(55.6)$ & $8(44.4)$ & $13(72.2)$ & $118(55.7)$ \\
\hline & Sometimes & $48(34.3)$ & $14(38.9)$ & $6(33.3)$ & $4(22.2)$ & $72(34)$ \\
\hline \multirow{3}{*}{$\begin{array}{l}\text { Do you dilate before inserting the } \\
\text { hysteroscope? }\end{array}$} & Always & $7(5)$ & $3(8.3)$ & $1(5.6)$ & 0 & $11(5.2)$ \\
\hline & Never & $36(25.7)$ & $8(22.2)$ & $1(5.6)$ & $3(16.7)$ & $48(22.6)$ \\
\hline & Sometimes & $97(69.3)$ & $25(69.4)$ & $16(88.9)$ & $15(83.3)$ & $153(72.2)$ \\
\hline \multirow{3}{*}{$\begin{array}{l}\text { Following collection of specimen, do you } \\
\text { carry out post-procedure cavity check? }\end{array}$} & Always & $63(45)$ & $7(19.4)$ & $4(22.2)$ & $2(11.1)$ & 76 (35.8) \\
\hline & Never & $12(8.6)$ & $4(11.1)$ & $2(11.1)$ & $9(50)$ & $27(12.7)$ \\
\hline & Sometimes & $65(46.4)$ & $25(69.4)$ & $12(66.7)$ & $7(38.9)$ & 109 (51.4) \\
\hline \multirow{3}{*}{$\begin{array}{l}\text { When carrying out post-procedure cavity } \\
\text { check, do you use suction to flush the cavity? }\end{array}$} & Always & $16(11.4)$ & $2(5.6)$ & $1(5.6)$ & 0 & $19(9)$ \\
\hline & Never & $84(60)$ & $22(61.1)$ & $13(72.2)$ & $17(94.4)$ & $136(64.2)$ \\
\hline & Sometimes & 40 (28.6) & $12(33.3)$ & $4(22.2)$ & $1(5)$. & $57(26.9)$ \\
\hline
\end{tabular}

$N=212$, with percentages in brackets. Grades of candidates are divided up in the columns

As shown at the bottom of Table 1, in total, $35.8 \%$ candidates (76/112) always carry out post-procedure cavity checks. A higher proportion of consultants $(45 \%)$ carry out post-procedure cavity checks compared to junior registrars $(22.2 \%)$ and clinical nurse specialists (11.1\%). Only $9 \%$ of candidates (19/212) use suction to flush the cavity to aid vision during the post-procedure cavity checks (16 consultants, 2 senior registrars and 1 junior registrar).

For the additional three questions asked to the 129 candidates from the BSGE, the biggest response given by 41.9\%; when asked what anatomical location they felt you are most likely to perforate during hysteroscopy, was the "posterior uterine wall in the anteverted uterus and the anterior uterine wall in the retroverted uterus' (Fig. 1). The majority (76\%) predicted dilatation as the stage of hysteroscopy most likely to cause uterine perforation (Fig. 2). Lastly, 41.1\% (53/129) use a standard proforma for documentation of their findings following hysteroscopy.

\section{Discussion}

Main findings

The results from this survey show varied practice amongst gynaecologists across the UK. This is reflected through limited information being available in the literature regarding safety aspects of hysteroscopy, specifically in relation to entry and specimen retrieval. There are guidelines available from the RCOG on best practice in outpatient hysteroscopy [2], but no guidelines available on inpatient diagnostic and operative hysteroscopy under general anaesthetic.

Table 2 Summary of response by candidates to the question of how they position the internal cervical os as visualised through the scope during insertion of a $30^{\circ}$ hyster scope

\begin{tabular}{|c|c|c|c|c|c|}
\hline \multirow{2}{*}{$\begin{array}{l}\text { How do you position the internal cervical os as visualised } \\
\text { through the } 30^{\circ} \text { hysteroscope? }\end{array}$} & \multicolumn{5}{|c|}{ Number (percentage) } \\
\hline & Consultants & Senior registrar & Junior registrar & $\begin{array}{l}\text { Clinical nurse } \\
\text { Specialist }\end{array}$ & Total \\
\hline Always 6 o'clock position & $42(30.2)$ & $15(44.1)$ & $8(44.4)$ & $6(46.2)$ & $71(34.8)$ \\
\hline Always 12 o'clock position & $12(8.6)$ & $4(11.8)$ & 0 & $1(7.7)$ & $17(8.3)$ \\
\hline The way the hysteroscope naturally goes & $52(37.4)$ & $6(17.6)$ & $3(16.7)$ & $5(38.5)$ & $66(32.4)$ \\
\hline $\begin{array}{l}6 \text { o'clock position for anteverted uterus, } 12 \text { o'clock position } \\
\text { for retroverted uterus }\end{array}$ & $23(16.5)$ & $6(17.6)$ & $4(22.2)$ & $1(7.7)$ & $34(16.7)$ \\
\hline $\begin{array}{l}12 \text { o'clock position for anteverted uterus, } 6 \text { o'clock position } \\
\text { for retroverted uterus }\end{array}$ & $10(7.2)$ & $3(8.8)$ & $3(16.7)$ & 0 & $16(7.8)$ \\
\hline
\end{tabular}


Table 3 Summary of instruments used for specimen retrieval during hysteroscopy

\begin{tabular}{llllll}
\hline $\begin{array}{l}\text { Instrument used for } \\
\text { specimen retrieval }\end{array}$ & Consultant & $\begin{array}{l}\text { Senior } \\
\text { registrar }\end{array}$ & $\begin{array}{l}\text { Junior } \\
\text { registrar }\end{array}$ & $\begin{array}{l}\text { Clinical } \\
\text { nurse } \\
\text { specialist }\end{array}$ & Total \\
\hline Polyp forceps & 49 & 9 & 6 & 7 & 71 \\
Currette & 38 & 9 & 6 & 5 & 58 \\
Versapoint & 15 & 1 & 0 & 0 & 16 \\
Myosure & 19 & 1 & 0 & 4 & 24 \\
Pipelle & 8 & 0 & 0 & 5 & 13 \\
$\begin{array}{l}\text { All of above 5 options } \\
\text { depending on }\end{array}$ & 61 & 25 & 9 & 3 & 98 \\
availability & & & & & 10 \\
Resectoscope & 7 & 2 & 0 & 1 & 4 \\
Truclear & 4 & 0 & 0 & 0 & \\
\hline
\end{tabular}

Candidates were able to give one or more responses and the columns separate out the different grades of gynaecologists

When asked if candidates perform a vaginal examination prior to hysteroscopy, $64.2 \%$ stated that they always do, $31.1 \%$ sometimes and $4.7 \%$ never. Literature highlights bimanual assessment being a vital step to perform to correctly identify the size, position and attitude of the uterus, helping to determine the direction to insert the hysteroscope, and reducing the risk of uterine perforation [9-11]. However, if the patient has had an ultrasound scan indicating the uterine position then this step may be omitted, provided the surgeon is aware of the ultrasound report.

Whether or not to sound the uterus prior to hysteroscopy is debatable, with limited evidence for its use in literature. In the survey, of concern, $10.4 \%$ of candidates stated that they always sound the uterus prior to insertion of the hysteroscope. Some articles report it as a useful step to help determine the length and direction of the internal os and uterine cavity, thereby reducing your chance of perforation and suspecting perforation when the sound goes beyond the expected size of the uterus [10-12]. However, it is another instrument introduced into the uterus, increasing the risk of perforation and should only be used on occasion with proper technique of a gentle approach holding the sound like a pen, not a skewer to avoid perforation [10].

Dilatation is reported to be when most cervical trauma and uterine perforations occur [5]. One study reported $50 \%$ of their perforations occurred during dilatation of the cervix [8]. Dilatation is not recommended for diagnostic procedures [1]. However,

\section{Chart demonstrating where candidates felt the most likely sites of uterine perforation are}

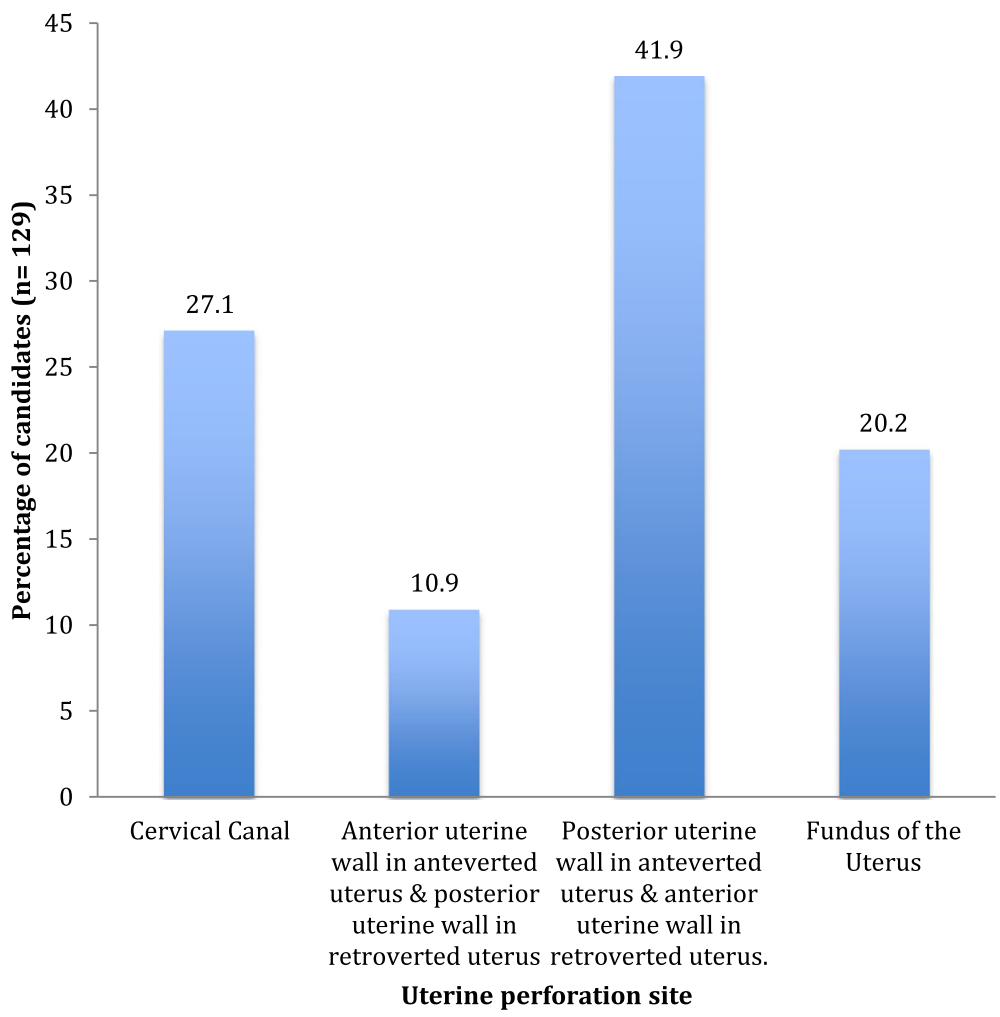

Fig. 1 Chart demonstrating where candidates (in percentages) felt the most likely anatomical location of uterine perforation is 


\section{Chart demonstrating which stage candidates feel is the most likely to result in uterine perforation}

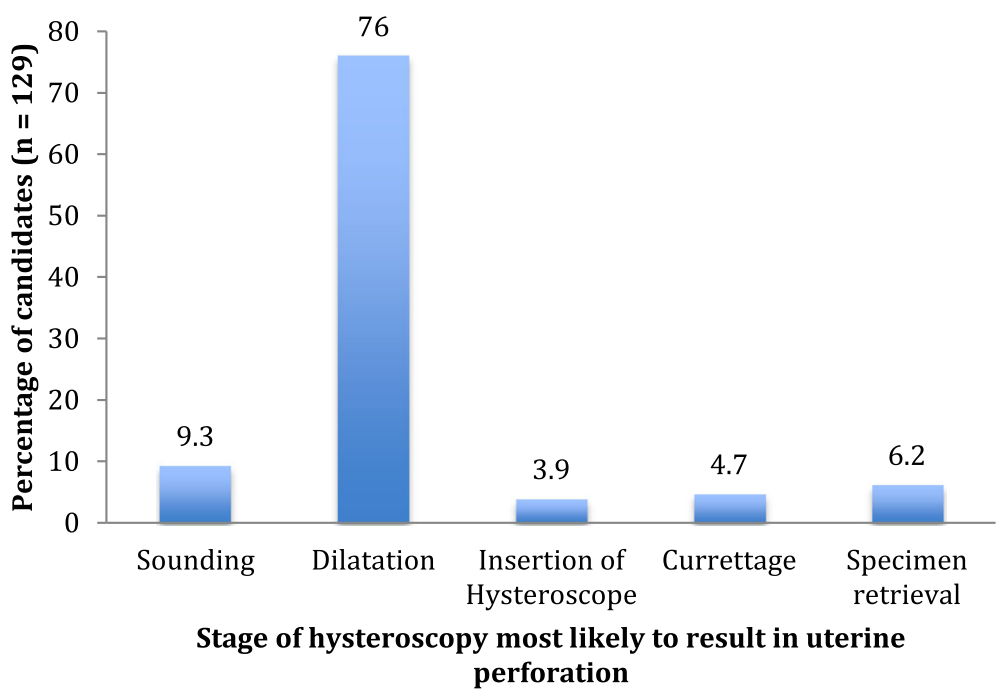

Fig. 2 Chart demonstrating the percentage of candidates who predicted which stage of hysteroscopy is the cause behind most uterine perforations seen

gradual cervical dilatation is sometimes required in cervical stenosis. Articles report the importance of avoiding excessive force and the use of half-size dilators to reduce the risk of perforation [9]. In the present study, candidates were aware of the risk of dilatation with $76 \%$ determining dilatation to be the commonest step to result in uterine perforation; however, $5.2 \%$ stated they always perform dilatation prior to insertion of the hysteroscope (Fig. 2).

There is limited information available on how to position the internal cervical os as visualised through the scope when inserting a $30^{\circ}$ hysteroscope. This was reflected in the study with only $16.7 \%$ knowing the correct technique. The correct technique to avoid perforation, for an anteverted uterus, is to guide the hysteroscope along the posterior cervical wall keeping the internal os at the 6 o'clock position and in a retroverted uterus to guide the hysteroscope along the anterior cervical wall keeping the internal os at the 12 o'clock position (see Fig. 3). The correct technique not only allows for a smooth procedure but also prevents perforation and creation of a false passage [13]. A review article titled, 'the perforated uterus' published in 2013 highlights the commonest site of uterine perforation being the anterior uterine wall, which was also the commonest response given by candidates in this study [9]. This

\section{Diagram demonstrating how to position the internal cervical os as visualised through the scope during the insertion of a $30^{\circ}$ Hysteroscope}

Anteverted Uterus

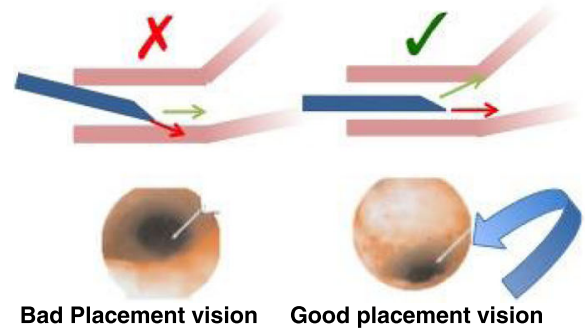

Retroverted Uterus

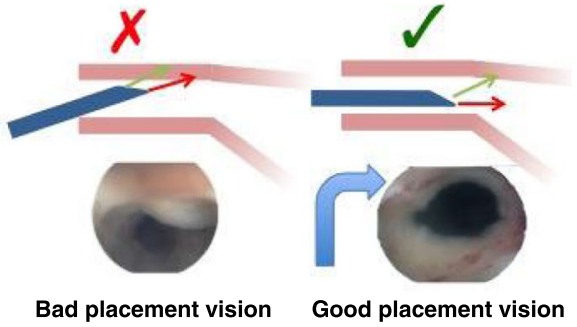

Fig. 3 Diagram demonstrating how to position the internal cervical os as visualised through the hysteroscope during insertion of the $30^{\circ}$ hysteroscope. The image to the left demonstrates the technique with an anteverted uterus to guide the hysteroscope along the posterior cervical wall keeping the internal os at the 6 o'clock position. The image to the right demonstrates the technique with a retroverted uterus to guide the hysteroscope along the anterior cervical wall keeping the internal os at the 12 o'clock position 
corresponds to the site of perforation in the retroverted uterus which being the less common uterine anatomy often catches the gynaecologist off guard, highlighting the importance of good technique in determining the attitude of the uterus to avoid this mistake.

Continual advancement in technology and improvement in surgical instruments has resulted in a range of instruments available for specimen retrieval. Some instruments including polyp forceps and curette have a higher chance of uterine perforation due to being a blind procedure compared to myosure and resectoscope, which are performed under direct vision. The survey demonstrates a range of instruments used resulting from different health board funds and training of the staff. It also reflects limited knowledge of the risks of using different instruments.

Post-procedure cavity checks aid identification of an unsuspected uterine perforation. Sudden loss of vision during hysteroscopic procedures due to collapse of the uterus and bleeding together with a large deficit of distension medium is highly suggestive of uterine perforation $[9,11]$. In this survey, only $35.8 \%$ always perform a post-procedure cavity check and $9 \%$ always use suction to aid vision during a post-procedure cavity check.

The study shows a range in practice amongst the different groups of practitioners. In general, a higher proportion of junior and senior registrars (88.9 vs 86.1\%) always perform a vaginal examination (VE) compared to the consultants (59.3\%) and nurse specialists (33.3\%). This is expected as consultants through years of experience, performing multiple hysteroscopies in their working day, do not necessarily perform a VE as they know what to expect. Double the proportion of junior registrars $(22.2 \%)$ always sound the uterus compared to $10.7 \%$ consultants, which might reflect what is being taught to the juniors. A higher proportion of consultants compared to registrars and nurse specialists perform postprocedure cavity checks. This would be expected, as consultants are more likely to do complex operative hysteroscopy with higher risk of perforation.

\section{Strengths and limitations}

This study provides a good overview about a national group of physicians and their methods of work. We were looking very specifically at entry techniques and specimen retrieval and hence the questionnaire focussed on this aspect. We did not include questions regarding other complications such as fluid absorption and its implications.

Limitations include a bias towards the practice in Wales as $39 \%$ of the responses were from Wales. Even though the study focused on inpatient hysteroscopy under general anaesthetic, it would have been good to expand on the differences in practice between outpatient hysteroscopy under local anaesthetic and inpatient hysteroscopy under general anaesthetic. Outpatient hysteroscopy uses a vaginoscopic approach; therefore, they are less likely to perform vaginal examination, sounding and dilatation and more likely to use ultrasound. This would help to also differentiate the difference between diagnostic and operative hysteroscopies.

\section{Conclusion}

The study highlights varied practice across the UK regarding safety aspects of hysteroscopy, in relation to entry and specimen retrieval. Some gynaecologists are still using questionable techniques. The high percentage of gynaecologists who sound and/or dilate the cervix before hysteroscopy, and the low rate of specialists who correctly know how to position the internal cervical os on the hysteroscope was surprising and raises the question of whether the juniors are being taught the correct techniques. There is a need for increased awareness of the risks of hysteroscopy and paramount precautions that should be performed routinely as part of their practice. Standardised guidelines regarding safety aspects of inpatient diagnostic and operative hysteroscopy, taking into account patient caveats, may be a beneficial tool to help bring about this change in practice, leading to a reduction in uterine perforation rates.

\section{Abbreviations}

BMI: Body mass index; BSGE: British Society of Gynaecological Endoscopy; RCOG: Royal College of Obstetricians and Gynaecologists; ST3-7: Specialitytraining registrar doctors in their 3rd to 7th year of training; UK: United Kingdom

\section{Acknowledgements}

None.

\section{Funding}

None required.

Availability of data and materials

All summarised in tables and figures in article. If you require the raw data, please contact us.

Declarations

None declared.

Authors' contributions

LG conceived and designed the study and revised the article for intellectual content. SHW helped design the study, collected the data, completed the statistical analysis and drafted the article. All authors approved the version for publication.

Ethics approval and consent to participate

No ethical approval was required as the survey was optional and anonymous and study aims explained to all candidates prior to performing the survey.

Consent for publication

Not applicable. 


\section{Competing interests}

The authors declare that they have no competing interests.

\section{Publisher's Note}

Springer Nature remains neutral with regard to jurisdictional claims in published maps and institutional affiliations.

Received: 1 November 2017 Accepted: 2 January 2018

Published online: 15 January 2018

\section{References}

1. Jansen FW et al (2000) Complications of hysteroscopy: a prospective, multicenter study. Obstet Gynaecol J 96(2):266-270

2. Best Practice in Outpatient Hysteroscopy (2011) Green-top Guideline No. 59. RCOG/BSGE Joint Guideline

3. Agostini A, Cravello L, Bretelle F, Shohai R, Roger V, Blanc B (2002) Risk of uterine perforation during hysteroscopic surgery. J Am Assoc Gynaecol Laparosc 9(3):264-267

4. Passini A, Belloni C (2001) Intraoperative complications of 697 consecutive operative hysteroscopies. Minerva Gynaecol J 53(1):13-20

5. Petrozza JC (2015) Hysteroscopy Treatment \& Management. In: Rivlin ME (ed) eMedicine.com Found at: http://emedicine.medscape.com/article/ 267021-treatment\#d13. Accessed 13 Oct 2017

6. Munro MG, Christianson LA (2015) Complications of hysteroscopic and uterine resectoscopic surgery. Clin Obstet Gynaecol 58(4):765-797

7. Cutner A, Erian J (1996) Who should have outpatient hysteroscopy? Gynaecol Endosc J 5:231-234

8. Paschopoulos M et al (2006) Safety issues of hysteroscopic surgery. N Y Acad Sci 1092:229-234

9. Shakir F, Diab Y (2013) The perforated uterus. Obstet Gynaecol 15:256-261

10. Hulka JF (2008) Surgical techniques: dilatation and curettage. Glob Libr Women's Med. https://doi.org/10.3843/GLOWM.10037

11. Bradley LD, Dayaratna SD (2008) Hysteroscopy. Gynaecol Board Rev Manual $11(4): 2-11$

12. Crane JMG (2007) How to overcome a resistant cervix for hysteroscopy and endometrial biopsy. Obstet Gynaecol Manag 19(11):37-46

13. Medhekar M Complications in hysteroscopy. Mumbai Obstet Gynaecol Soc Found at: http://www.mogsonline.org/complications_in_enewsletter_article. html. Accessed 13 Oct 2017

\section{Submit your manuscript to a SpringerOpen ${ }^{\circ}$ journal and benefit from:}

- Convenient online submission

- Rigorous peer review

- Open access: articles freely available online

- High visibility within the field

- Retaining the copyright to your article 